\title{
Screening of differentially expressed proteins in psoriasis vulgaris by two-dimensional gel electrophoresis and mass spectrometry
}

\author{
YINAN DAI $^{1}$, QINGRUI ZHANG ${ }^{1,2}$, YI JIANG ${ }^{2}$, LU YIN $^{1}$, XIAODONG ZHANG $^{1}$, YANG CHEN $^{2}$ and XINZE CAI ${ }^{2}$ \\ ${ }^{1}$ Department of Dermatology, 202 Hospital of PLA; ${ }^{2}$ Central Laboratory, The First Affiliated Hospital, \\ China Medical University, Shenyang, Liaoning 110001, P.R. China
}

Received July 1, 2015; Accepted September 22, 2016

DOI: 10.3892/etm.2017.5012

\begin{abstract}
The aim of the present study was to elucidate differentially expressed proteins in lesional tissues of psoriasis vulgaris (PV) and normal tissues. Lesional skin tissues were collected from PV patients, along with normal skin tissues from healthy individuals. The protein content of the samples was extracted and then separated by two-dimensional gel electrophoresis (2-DGE). Any proteins that were differentially expressed in the lesional skin of PV patients compared with the healthy controls were analyzed by mass spectrometry and bioinformatics. In the stratum corneum and dermis of PV patients, the total number of proteins identified by 2 -DGE was $1,969 \pm 21$ and $1,928 \pm 49$, respectively. Of these, 30 proteins were differentially expressed in the PV patients, of which 14 were identified as: Type 1 keratin cytoskeleton proteins (including $\mathrm{K} 1 \mathrm{C} 10, \mathrm{~K} 1 \mathrm{C} 14, \mathrm{~K} 1 \mathrm{C} 15$ and $\mathrm{K} 1 \mathrm{C} 16$ ); the type 2 keratin cytoskeleton protein, $\mathrm{K} 2 \mathrm{C} 1$; actin-associated proteins (including ARP3, ACTA and ACTBM); prohibitin; heat shock proteins (HSPB1 and CH60); centrosome protein, CP135; and membrane associated proteins (including ANXA4 and ANXA5). The differential expression of protein between PV lesions and normal tissue can be considered as pathological biomarker. Elucidating the abnormal regulation of these proteins can provide mechanism of the development of PV and may contribute to significant approaches for PV treatments.
\end{abstract}

\section{Introduction}

Psoriasis is a common and recurrent chronic inflammatory skin disease (1). Histopathological analyses have previously demonstrated thickening of the stratum corneum, dyskeratosis, thinner or disappeared granular layer, thickening acanthosis

Correspondence to: Dr Qingrui Zhang, Department of Dermatology, 202 Hospital of PLA, 5 Guangrong Road, Shenyang, Liaoning 110001, P.R. China

E-mail: zhangqingrui110003@126.com

Key words: differentially expressed proteins, psoriasis vulgaris, two-dimensional gel electrophoresis, mass spectrometry and cuticle angiogenesis in patients with psoriasis $(2,3)$. In recent years, the development of proteomics has provided an effective way to identify sensitive and specific markers of disease $(4,5)$. Abnormal protein expression in psoriasis vulgaris (PV) patients usually leads to skin cell death, immune response and inflammatory reaction in psoriatic skin (6).

By separating peripheral blood and tissue fluid from PV patients and normal individuals, differentially expressed proteins have been previously identified using two-dimensional gel electrophoresis (2-DGE) and matrix-assisted laser desorption/ionization time-of-flight/time-of-flight mass spectrometry (MALDI-TOF-TOF-MS) (7,8). Using bioinformation technologies and proteomics, the markers of PV can be identified.

In the present study, 2-DGE was performed for protein separation, and then differentially expressed proteins were identified by MALDI-TOF-TOF-MS and bioinformatics analysis. The differentially expressed proteins were analyzed by comparing the skin lesions of PV patients and normal human tissues, providing an insight into the pathogenesis of PV that may assist in identifying potential therapeutic targets.

\section{Materials and methods}

Materials. Specimens were collected from 16PV patients (8 male and 8 female; mean age, 35.5 years; age range, 19-60 years) who were admitted to the Department of Dermatology of the 202 Hospital of PLA (Shenyang, China). In addition, specimens were collected from 20 healthy individuals without PV (outpatient subjects; 10 male and 10 female) who were recruited as the control group. Protein determination bi-directional quantification kit, 2D clean-up kit, MS identification reagent, dithiothreitol (DTT) and iodoacetamide (IAA) were purchased from GE Healthcare Life Sciences (Little Chalfont, UK). Solid PH gradient dry strip [immobilized pH gradient (IPG) 3-10; $24 \mathrm{~cm}$ ], electrophoresis reagents, acrylamide/bis-acrylamide, glycine, urea, Tris, SDS and CHAPS were obtained from Amresco LLC (Solon, OH, USA). Peptide standard and acetonitrile were obtained from Merck KGaA (Darmstadt, Germany), trifluoroacetic acid (TFA) was from Sigma-Aldrich (Merck $\mathrm{KGaA}$ ), while matrix $\alpha$-cyano-4-hydroxycinnamic acid (CCA) and trypsin were from Promega Corporation (Madison, WI, USA). All the experiments were approved by the institutional Review Board and obtained signed documents of informed consent from the patients. 
A

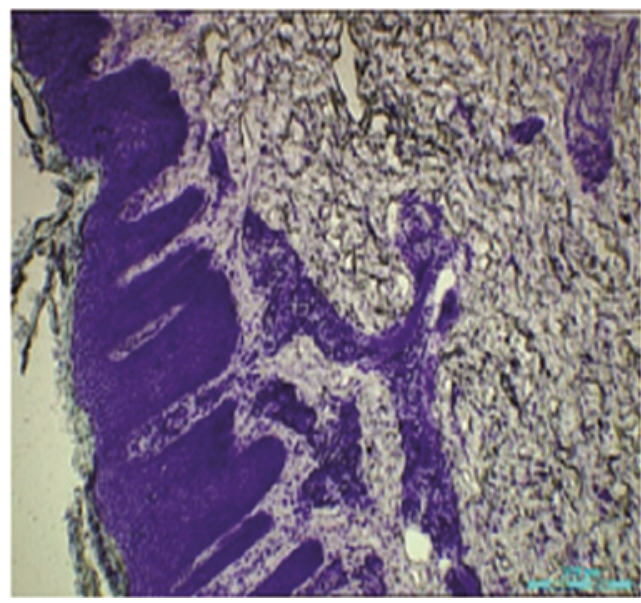

B

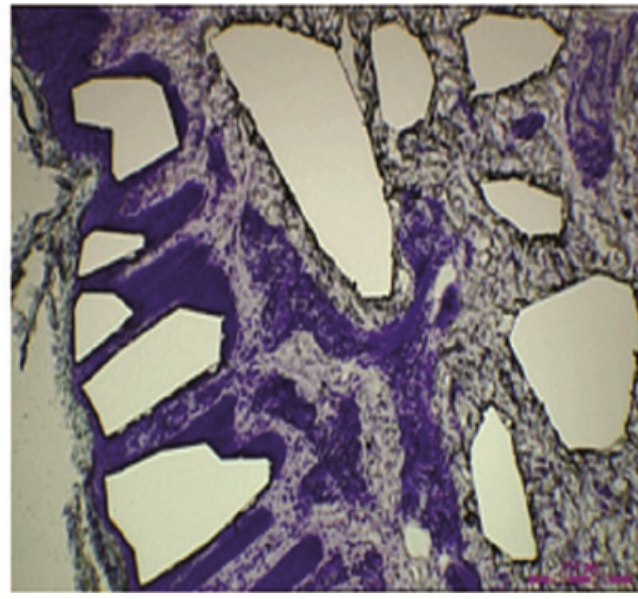

Figure 1. Microscope images of psoriasis vulgaris lesions (A) prior to and (B) following sectioning, observed with methylene blue staining (magnification, x10).

Protein extraction. The skin layer was collected from skin lesions of PV patients and from normal control individuals. The collected specimens were $0.5 \times 0.5 \mathrm{~cm}$ in size and were preserved at $-70^{\circ} \mathrm{C}$. Next, the frozen tissue sections with thickness of 16-18 $\mu \mathrm{m}$ were transferred on Leica film slides and then cut using a Leica laser cutting instrument (Leica Microsystems, Wetzlar, Germany). The specimens were observed with methylene blue staining, as shown in Fig. 1. Samples from the stratum corneum and dermis tissue were obtained. Subsequently, the tissue was then placed in the $0.5-\mathrm{ml}$ centrifuge tube and protein was extracted using the 2D clean-up kit. Protein concentration was determined using a BCA kit. Equal quantities of protein (40 $\mu \mathrm{g}$ in $10 \mu \mathrm{l}$ solution) were extracted according to the different protein concentration, and the proteins were collected from both the dermal layer and the stratum corneum of PV patients. The same treatment was applied in the control group. Samples (100 $\mu \mathrm{l}$ each) were then subjected to gel electrophoresis.

2-DGE. Each SDS-polyacrylamide gel was loaded with $100 \mu \mathrm{g}$ protein and mixed with a solution containing $7 \mathrm{~mol} / 1$ urea, $2 \mathrm{M}$ thiourea, $4 \%$ CHAPS and $0.2 \%$ ampholyte, with a total sample volume of $290 \mu \mathrm{l}$. Following hydration of the IPG adhesive strip (24 cm; pH 3-10; non-linear), mineral oil was used to prevent exposure to the air. The isoelectric focusing procedure was set to $30 \mathrm{~V}$ for $6 \mathrm{~h}, 60 \mathrm{~V}$ for $6 \mathrm{~h}, 500 \mathrm{~V}$ for $1 \mathrm{~h}, 1,000 \mathrm{~V}$ for $1 \mathrm{~h}, 8,000 \mathrm{~V}$ for $10 \mathrm{~h}$, and the total voltage time product was $64,000 \mathrm{~V} / \mathrm{h}$. Subsequent to isoelectric focusing, the IPG strip was preserved in the SDS equilibrium solution (containing $6 \mathrm{M}$ urea, $2 \% \mathrm{SDS}$ and $0.02 \%$ bromophenol blue liquid reserves) for $15 \mathrm{~min}$. After equilibrium was achieved, the IPG strip was placed above the $12.5 \%$ uniform polyacrylamide gel, and $10 \mu \mathrm{l}$ protein marker was added on the SDS-polyacrylamide gel. Any air bubbles were removed and the gel was sealed using anhydrous ethanol. Next, 2-DGE was performed until the bromophenol blue reached the bottom edge of the gel, with a total duration of $20 \mathrm{~h}$. Cy3 and Cy5 fluorescence staining (Rongbio, Shanghai, China) was then performed in the samples from the dermis and corneous layer groups in PV patients and controls. The images were subjected to intensity correction, point detection, background subtraction, homogenization and matching processing by DeCyder 2D version 6.5 software (GE Healthcare Life Sciences).
Enzymatic digestion and mass spectrometric identification. The differentially expressed protein spots observed by 2-DGE were selected; the software DeCyder 2D 6.5 (GE Healthcare Life Sciences) was used to analyze it. Next, the gel was digested by $20 \mu \mathrm{g} / 1$ trypsin at $37^{\circ} \mathrm{C}$ overnight, and the peptide extraction was dissolved in $50 \%$ acetonitrile and $0.5 \%$ TFA. The obtained peptide were dissolved in $50 \%$ acetonitrile $-0.5 \%$ trifluoroacetate and then mixed with saturated matrix CCA at 1:1. The samples were loaded onto the target instrument, dried and subjected to MALDI-TOF-TOF-MS detection, as previously described (9).

Protein identification and database search. The peptide mass fingerprint data was searched in the protein sequence database SwissProt (uniprot.org/) and the search engine Mascot (matrixscience.com). Parameter settings were as follows: Cysteine abbreviated as Cys (carbamidomethyl); variable modification abbreviated as M (oxidation); each peptide was set as one incomplete cleavage site peptide fragment with a maximum allowable error of $\pm 100 \mathrm{ppm}$. Protein matching scores of $>36$ indicated that differences were statistically significant $(\mathrm{P}<0.05)$, determined using Mascot. Through MALDI-TOF-TOF-MS (9), the proteins were identified and the functions were established.

\section{Results}

2-DGE. The 2-DGE results of the stratum corneum and dermis samples obtained from PV patients and normal controls were analyzed using the DeCyder 2D version 6.5 image analysis software. As shown in Fig. 2, the protein spots demonstrated good repeatability and stability. The differentially expressed protein spots in the stratum corneum and dermis of PV patients were $1,969 \pm 21$ and $1,928 \pm 49$, respectively. One piece of gel was set as control, with the average matching rate of 78.2 and $76.3 \%$. Protein expression that showed an $>2$-fold difference between the patients and controls, and when the same changes appeared in three samples, then the protein was regarded as being differentially expressed.

MS identification results. In the present study, the proteins from the stratum corneum and dermis layer of skin lesions 
Table I. Mass spectrometry results of differentially expressed proteins.

\begin{tabular}{|c|c|c|c|c|c|c|c|c|}
\hline \multirow[b]{2}{*}{ Protein } & \multirow[b]{2}{*}{ Protein definition } & \multirow[b]{2}{*}{$\begin{array}{l}\text { MW } \\
(\mathrm{kDa})\end{array}$} & \multirow[b]{2}{*}{$\mathrm{pI}$} & \multirow[b]{2}{*}{$\%^{\mathrm{a}}$} & \multirow{2}{*}{$\begin{array}{l}\text { Protein } \\
\text { matching } \\
\text { score }^{\mathrm{b}}\end{array}$} & \multicolumn{3}{|c|}{ Differential expression $^{\mathrm{c}}$} \\
\hline & & & & & & $\begin{array}{l}\text { Stratum } \\
\text { corneum }^{\mathrm{c}}\end{array}$ & Dermis $^{\mathrm{d}}$ & Variability \\
\hline $\mathrm{K} 1 \mathrm{C} 10$ & Keratin, type I cytoskeletal 10 & 59 & 5.13 & 7 & 106 & $\uparrow$ & & 2.19 \\
\hline $\mathrm{K} 1 \mathrm{C} 14$ & Keratin, type I cytoskeletal 14 & 51.9 & 5.09 & 6 & 103 & $\uparrow$ & & 2.59 \\
\hline $\mathrm{K} 1 \mathrm{C} 15$ & Keratin, type I cytoskeletal 15 & 49.4 & 4.71 & 5 & 43 & $\downarrow$ & & -3.81 \\
\hline $\mathrm{K} 1 \mathrm{C} 16$ & Keratin, type I cytoskeletal 16 & 51.6 & 4.99 & 8 & 267 & $\uparrow$ & $\downarrow$ & $2.15 /-5.15$ \\
\hline $\mathrm{K} 2 \mathrm{C} 1$ & Keratin, type II cytoskeletal 1 & 66.2 & 8.15 & 2 & 36 & $\uparrow$ & & 2.83 \\
\hline ARP3 & Actin-related protein 3 & 47.8 & 5.61 & 7 & 184 & $\uparrow$ & & 2.32 \\
\hline ACTA & Actin, aortic smooth muscle & 42.4 & 5.23 & 4 & 141 & $\uparrow$ & $\downarrow$ & $2.39 /-3.67$ \\
\hline АCTBM & Putative $\beta$-actin-like protein 3 & 42.3 & 5.91 & 7 & 181 & $\uparrow$ & & 6.28 \\
\hline HSPB1 & Heat shock protein $\beta 1$ & 22.8 & 5.98 & 8 & 139 & $\downarrow$ & & -2.45 \\
\hline CH60 & $60 \mathrm{kDa}$ heat shock protein & 61.2 & 5.7 & 6 & 178 & $\uparrow$ & & 3.13 \\
\hline PHB & Prohibitin & 29.8 & 5.57 & 12 & 47 & $\uparrow$ & & 2.76 \\
\hline CP135 & Centrosomal protein of $135 \mathrm{kDa}$ & 133.9 & 5.87 & 6 & 40 & $\uparrow$ & $\downarrow$ & $2.23 /-2.41$ \\
\hline ANXA4 & Annexin A4 & 36.1 & 5.84 & 7 & 116 & $\downarrow$ & & -2.35 \\
\hline ANXA5 & Annexin A5 & 36 & 4.94 & 7 & 185 & $\uparrow$ & & 2.52 \\
\hline
\end{tabular}

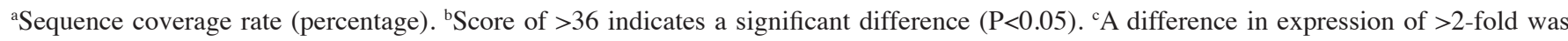
considered to be statistically significant. ${ }^{\mathrm{d}}$ These three proteins were downregulated in the dermis. $(\uparrow$ indicates upregulation and $\downarrow$ indicates downregulation). MW, molecular weight; pI, isoelectric point.
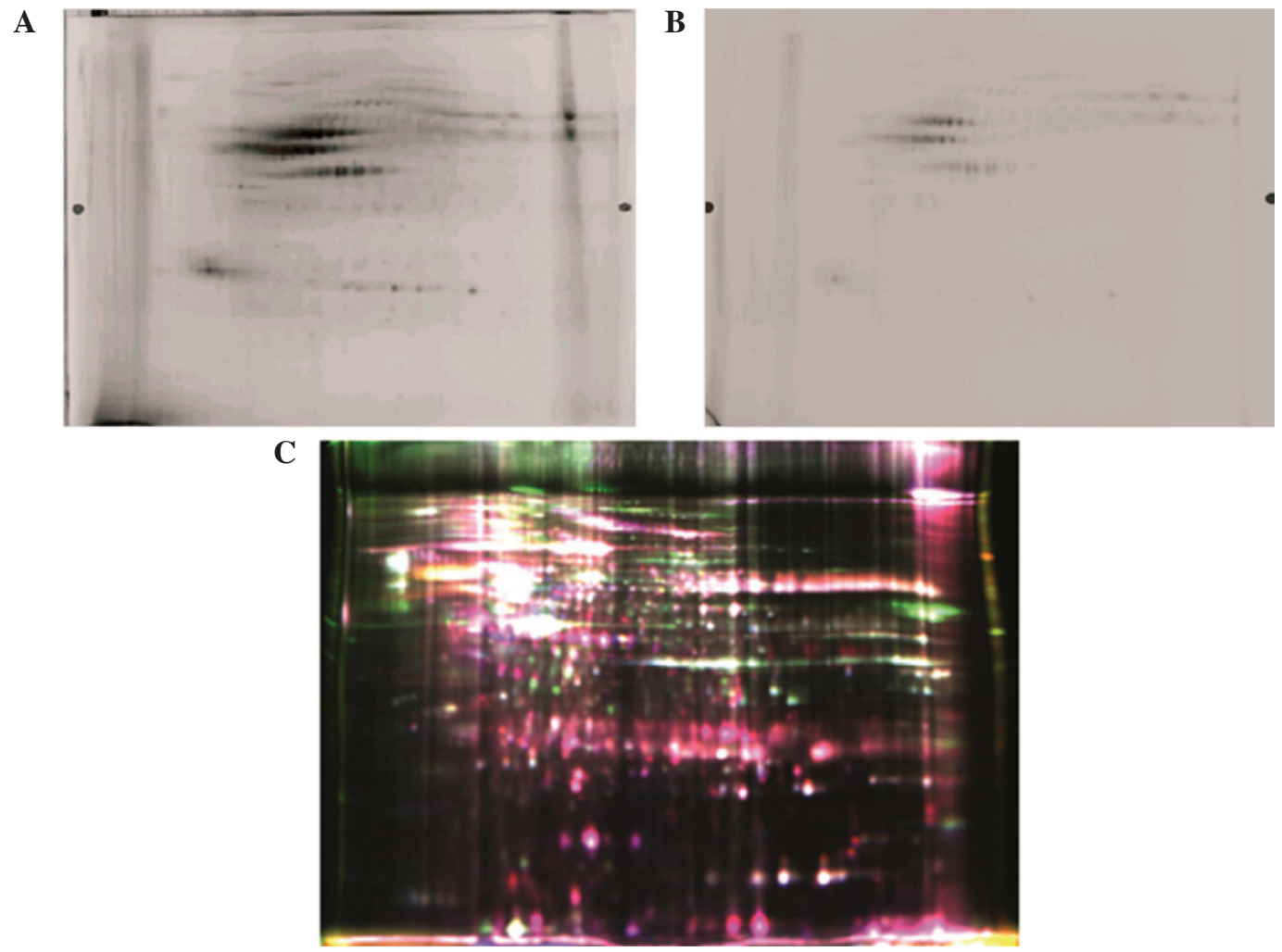

Figure 2. Gel map of stratum corneum in patients with PV using (A) Cy3 and (B) Cy5 staining. (C) Fluorescent gel map of stratum corneum in patients with PV. PV, psoriasis vulgaris.

from PV patients and normal control individuals were investigated. According to the MALDI-MS and bioinformatics analysis, 30 differentially expressed proteins were identified and 14 proteins meaningful to the present are presented in Table I. The identified proteins can be divided into the following categories: Keratin, type I cytoskeletal 

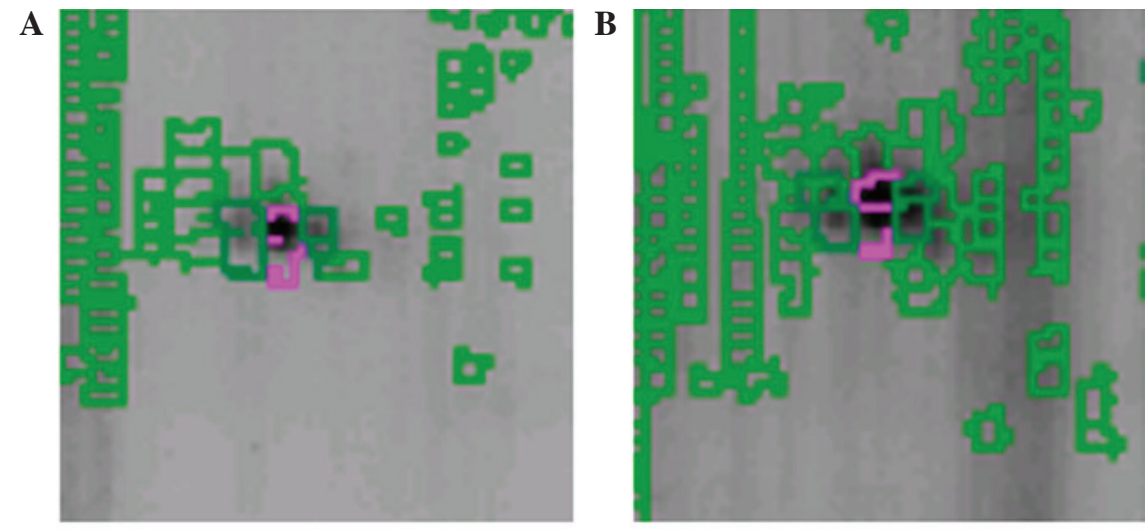

C

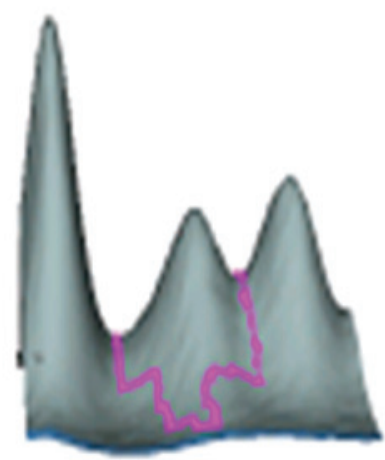

D

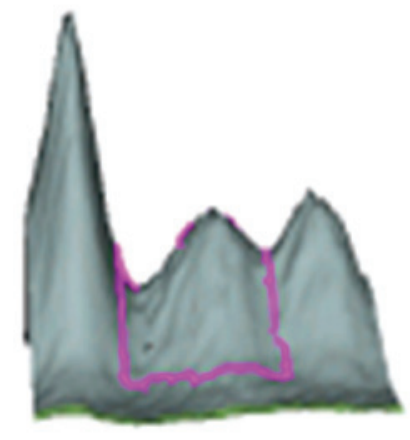

Figure 3. Location and three-dimension representation of CP135 in the gel. Location of CP-135 in the gel from (A) the control group dermis and (B) the psoriasis group's dermis. Three-dimensional images of CP-135 in the gels from (C) the control group dermis and (D) the psoriasis group dermis.

(K1C) proteins, including $\mathrm{K} 1 \mathrm{C} 10, \mathrm{~K} 1 \mathrm{C} 14, \mathrm{~K} 1 \mathrm{C} 15$ and $\mathrm{K} 1 \mathrm{C} 16$; keratin, type 2 cytoskeletal 1 (K2C1) protein; actin-associated proteins, including actin-related protein 3 (ARP3), actin aortic smooth muscle (ACTA2), putative $\beta$-actin-like protein 3 (ACTBM); heat shock family proteins, including heat shock protein $\beta 1$ (HSPB1) and $60 \mathrm{kDa}$ heat shock protein (CH60); prohibitin (PHB); centrosomal protein of $135 \mathrm{kDa}$ (CP135); and membrane-associated proteins, including annexin A4 (ANXA4) and ANXA5 (Table I). Fig. 3 demonstrates the location and three-dimension representation of CP135 on the gel.

Differentially expressed proteins in the stratum corneum of $P V$ patients. All 14 identified proteins were differentially expressed in the stratum corneum of PV patients. Of these, 11 proteins were upregulated in $\mathrm{PV}$ patients compared with the control tissues, including $\mathrm{K} 1 \mathrm{C} 10, \mathrm{~K} 1 \mathrm{C} 14, \mathrm{~K} 1 \mathrm{C} 16, \mathrm{~K} 2 \mathrm{C} 1$, ARP3, ACTA, ACTBM, CH60, PHB, CP135 and ANAX5. By contrast, 3 proteins were downregulated in the stratum corneum of PV patients, including K1C15, HSPB1 and ANAX4 (Table I).

Differentially expressed proteins in the dermis of $P V$ patients. In the dermis of PV patients, the proteins K1C16, ACTA and CP135 were downregulated compared with the control tissues. These three proteins were upregulated in the stratum corneum, but downregulated in the dermis (Table I).

\section{Discussion}

Previous studies on PV serum proteomic MS have provided a scientific basis for the pathogenesis of PV (10-12). However, there is a possibility that the proteins at high abundance in the samples may affect the detection of those at low abundance. If direct investigation of proteins in the PV lesional stratum corneum and dermis can be performed, such influence can be avoided, resulting in more accurate and reliable test results. The results of the present study demonstrated that numerous cytoskeletal proteins (including K1C10, K1C14, K1C15, K1C16 and $\mathrm{K} 2 \mathrm{C} 1$ ) were highly expressed in the cuticle lesions of PV patients. Bhawan et al (13) examined lesional and non-lesional samples from PV patients, as well as normal human samples, by immunohistochemical staining. The authors identified that $\mathrm{K} 1 \mathrm{C} 16$ expression was high in PV patient samples, which is similar to the results observed in the present study. In addition, $\mathrm{K} 1 \mathrm{C} 16$ was also found to be upregulated in non-lesional skin samples. Therefore, $\mathrm{K} 1 \mathrm{C} 16$ can be used as a marker for monitoring preclinical PV (13).

K1C15 expression results in incompatible keratinocyte formation, and $\mathrm{K} 1 \mathrm{C} 15$ gene downregulation can maintain activation phenotype $(14,15)$. Thus, regulation of the expression of $\mathrm{K} 1 \mathrm{C} 15$ can shorten the course of a disease. A previous study has suggested that $\mathrm{K} 1 \mathrm{C} 10$ is highly expressed in skin tissues (16), which is in line with the findings of the current study. $\mathrm{K} 1 \mathrm{C} 10$ is rich in proteoglycans containing leucine and keratan sulfate, and is a component of type I collagen fiber serving a key role in collagen fiber tissues. In addition, $\mathrm{K} 2 \mathrm{C} 1$ is reported to widely exist in elastic fibers, which are necessary components of the skin (17). $\mathrm{K} 2 \mathrm{C} 1$ is located at the extracellular matrix in the skin tissue and dynamic connective ligament, which endows elastic recoil for the tissue. In the present study, all the aforementioned highly expressed keratin-associated proteins were found to be upregulated. 
Whether these upregulated proteins can serve as diagnostic markers for PV requires further investigation.

Actin has been demonstrated to be important during the mitotic phase of the cell cycle (18). As a component of the actin filament nucleation ARP2/3 complex, ARP3 serves a key role in mitosis. Actin is widely detected in blood vessels. Its high expression in the cuticle lesions of PV patients suggested the hyperplasia of blood vessel. In the current study, ARP3, ACTA and ACTBM were found to be increased in the stratum corneum of PV patients, which further confirmed the vascular hyperplasia of PV patients. If the expression of actin can be reduced, the formation of skin lesions resulting from angiogenesis may be inhibited, thereby providing a new inside for the investigation of immunotherapy for PV.

The annexin family is a type of structure-associated calcium-dependent phospholipid binding protein superfamily. Annexin is widely distributed in various tissues and cells, and is known to participate in various cellular activities through the regulation of inflammation, immune response, cell differentiation, proliferation, apoptosis and cell signal transduction. Zimmermann et al (19) have suggested that ANXA4 may be involved in cell growth, differentiation and transformation in the renal medulla tumors. In the current study, downregulation of ANXA4 was observed in the stratum corneum of PV lesions, leading to uncontrolled cell proliferation in the PV lesions, which further resulted in hyperkeratosis of the epidermis formation. By contrast, the results of the study also indicated that ANXA5 was highly expressed in the stratum corneum of patients with PV. In rheumatoid arthritis and other diseases of the immune system, the protein levels of ANXA5 are also enhanced (20). ANXA5 is mainly expressed in the cytoplasm of squamous cell carcinoma of the uterine cervix, and its mRNA expression has been found to gradually increase with progressive cancer cell differentiation (21). The increased expression of ANAX5 may lead to decreased cell differentiation of the stratum corneum cells in PV lesions. It has been confirmed that, in the presence of $\mathrm{Ca}^{2+}$, ANXA5 hinders the recognition and binding of apoptotic cells by the phagocytic cells, thereby inhibiting the process of apoptosis (22). High expression levels of ANAX5 in PV lesions may also inhibit the process of cell apoptosis, resulting in epidermal cell hyperplasia and the emergence of PV-like lesions.

Heat shock protein is a type of heat-induced protein that is highly conserved in all living cells (23), and serves important physiological roles. Upregulation of heat shock protein protects cells from stress-associated response (24). An increased expression of heat shock protein can inhibit skin cell apoptosis and inflammation, and is induced by UV radiation through multiple signal transduction pathways and heat shock transcription factors. UV radiation may also exert an adaptive protection function by heat shock protein phosphorylation and translocation (25). Thus, upregulation of HSPB1, a heat shock protein family member, in epidermis exposed to UV radiation is correlated with the adaptive protection process (26). In the present study, the expression of HSPB1 was significantly reduced in the lesions of patients with PV. Boxman et al (27) has demonstrated that $\mathrm{UV}$ radiation causes an increase the expression of HSPB1, which serves as a self-protective mechanism of epidermal cells, thereby restoring the normal morphology and function of the skin. The current study observed that $\mathrm{CH} 60$ was upregulated in lesions of patients with PV, which is in agreement with the results of a previous study (28). Furthermore, it has previously been identified that the cascade reaction of inflammatory lymphocytes in the serum of patients with palmoplantar pustulosis and enhanced expression of $\mathrm{CH} 60$ significantly increased the incidence of PV (29).

In conclusion, the present study successfully established a platform for investigation of $\mathrm{PV}$ protein makers using proteomic technologies. K1C10, K2C1, ARP3, ANXA4, ANXA5 and CH60 may be possible PV pathogenesis markers. The present study provided further inside on PV pathology that may assist in the future investigation of immune therapy techniques for PV.

\section{References}

1. Barker JN: Psoriasis as a T cell-mediated autoimmune disease. Hosp Med 59: 530-533, 1998.

2. Shakery K and Reich K: Psoriasis-clinical picture and current therapy. Med Monatsschr Pharm 32: 335-344; quiz 345-346, 2009 (In German).

3. Reich A and Szepietowski J: Genetic and immunological aspects of the pathogenesis of psoriasis. Wiad Lek 60: 270-276, 2007 (In Polish).

4. Nickoloff BJ, Xin H, Nestle FO and Qin JZ: The cytokine andchemokine network in psoriasis. Clin Dermatol 25: 568-573, 2007.

5. Murphy M, Kerr P and Grant-Kels JM: The histopathologic spectrum of psoriasis. Clin Dermatol 25: 524-528, 2007.

6. Ryu J, Park SG, Park BC, Choe M, Lee KS and Cho JW: Proteomic analysis of psoriatic skin tissue for identification of differentially expressed proteins: Up-regulation of GSTP1, SFN and PRDX2 in psoriatic skin. Int J Mol Med 28: 785-792, 2011.

7. Macdonald N, Cumberbatch M, Singh M, Moggs JG, Orphanides G, Dearman RJ, Griffiths CE and Kimber I: Proteomic analysis of suction blister fluid isolated from human skin. Clin Exp Dermatol 31: 445-448, 2006.

8. Dearman RJ, Bhushan M, Cumberbatch M, Kimber I and Griffiths CE: Measurement of cytokine expression and Langerhans cell migration in human skin following suction blister formation. Exp Dermatol 13: 452-460, 2004.

9. Cai DX, Tan FJ, Ma WY, Zhong H and Sun Q: Screening for psoriasis-associated proteins by serological proteome analysis. Zhonghua Pi Fu Ke Za Zhi 46: 168-171, 2013 (In Chinese)

10. Rana A, Minz RW, Aggarwal R, Sharma S, Pasricha N, Anand S and Singh S: A comparative proteomic study of sera in paediatric systemic lupus erythematosus patients and in healthy controls usin MALDI-TOF-TOF and LC MS-Apolot study. Pediatr Rheumatol Online J 10: 24, 2012.

11. Sun RS, Chen XH and Hu JM: Proteomic analysis of proteins expressed in psoriatic lesions, Modern medicine 38: 144-147, 2010.

12. Yin GH, Fan $X$ and Zhang KM: In vitro study of T lymphocyte of peripheral blood in patients with psoriasis and influence of Ki67, C-Myc and Bcl-xLprotein in horny cells. Chinese Journal of immunology 22: 1150-1157, 2006.

13. Bhawan J, Bansal C, Whren K and Schwertschlag U; IL-11 Psoriasis Study Group: K16 expression in uninvoloved psoriatic skin: A possible marker of pre-clinical psoriasis. J Cutan Pathol 31: 471-476, 2004.

14. Leigh IM, Navsaria H, Purkis PE, McKay IA, Bowden PE and Riddle PN: Keratins (K16 and K17) as markers of keratinocyte hyperproliferation in psoriasis in vivo and in vitro. $\mathrm{Br}$ J Dermatol 133: 501-511, 1995.

15. Waseem A, Dogan B, Tidman N, Alam Y, Purkis P, Jackson S, Lalli A, Machesney M and Leigh IM: Keratin 15 expression in stratified epithelia: Downregulation in activited keratinocytes. J Invest Dermatol 112: 362-369, 1999. 
16. Taverna D, Nanney LB, Pollins AC, Sindona G and Caprioli R: Spatial mapping by imaging mass spectrometry offers advancements for rapid definition of human skin proteomic signatures. Exp Dermatol 20: 642-647, 2011.

17. Cain SA, McGovern A, Small E, Ward LJ, Baldock C, Shuttleworth A and Kielty CM: Defining elastic fiber interactions by molecular fishing: An affinity purification and mass spectrometry approach. Mol Cell Proteomics 8: 2715-2732, 2009

18. Mitsushima M, Aoki K, Ebisuya M, Matsumura S, Yamamoto T, Matsuda M, Toyoshima F and Nishida E: Revolving movement of a dynamic cluster of actin filaments during mitosis. J Cell Biol 191: 453-462, 2010.

19. Zimmermann U, Balabanov S, Giebel J, Teller S, Junker H, Schmoll D, Protzel C, Scharf C, Kleist B and Walther R: Increased expression and altered location of annexin IV in renal clear cell carcinoma: A possible role in tumour dissemination. Cancer Lett 209: 111-118, 2004.

20. Röhner E, Matziolis G, Perka C, Füchtmeier B, Gaber T, Burmester GR, Buttgereit $\mathrm{F}$ and Hoff P: Inflammatory synovial fluid microenvironment drives primary human chondrocytes to actively take part in inflammatory joint diseases. Immunol Res 52: 169-175, 2012.

21. Wang LP, Li X and Xu Q: The expression of annexin A5 in different differentiated human cervical squamous cell carcinoma and clinical significance. Tianjin Medical 40: 648-650, 2012.

22. Van Heerde WL, de Groot PG and Reutelingsperger CP: The complexity of the phospholipid binding protein Annexin V. Thromb Haemost 73: 172-179, 1995.
23. Ishihara K, Ando T, Kosugi M, Kato T, Morimoto M, Yamane G, Takahashi S, Ogiuchi H and Okuda K: Relationgships between the onset of pustulosis palmaris et plantaris, periodontitis and bacterial heat shock proteins. Oral Microbiol Immunol 15: 232-237, 2000.

24. Hayshi M, Fujihara K, Beder LB, Yamamoto Y, Hotomi M and Yamanaka N: Pathogenic role of tonsillar lymphocytes in associated with HSP60/65 in Pustulosis palmaris et plantaris. Auris Nasus Larynx 36: 578-585, 2009.

25. Seung NR, Park EJ, Kim CW, Kim KH, Kim KJ, Cho HJ and Park HR: Comparison of expression of heat-shock protein 60 , Toll-like receptors 2 and 4, and T-cell receptor gammadelta in plaque and guttate psoriasis. J Cutan Pathol 34: 903-911, 2007.

26. Becker B, Vogt T, Landthaler M and Stolz W: Detection of differentially regulated genes in keratinocytes by cDNA array hybridization: Hsp27 and other novel players in response to artificial ultraviolet radiation. J Invest Dermatol 116: 983-988, 2011.

27. Boxman IL, Kempenaar J, de Haas E and Ponec M: Induction of HSP27 nuclear immunoreactivity during stress is modulated by vitamin C. Exp Dermatol 11: 509-517, 2002.

28. Bayramgürler D, Ozkara SK, Apaydin R, Erçin C and Bilen N: Heat shock proteins 60 and 70 expression of cutaneous lichen planus: Comparison with normal skin and psoriasis vulgaris. J Cutan Pathol 31: 586-594, 2004.

29. Ergun T, Ince U, Ekşioğlu-Demiralp E, Direskeneli $H$, Gürbüz O, Gürses L, Aker F and Akoğlu T: HSP 60 expression in cocutaneous lesions of Behçet's disease. J Am Acad Dermatol 45: 904-909, 2001. 